\title{
El método de los astrólogos en los natalicios: los cuatro ciclos ${ }^{1}$
}

\section{The method of the astrologers in nativities: the four cycles}

\author{
Montse DÍAZ-FAJARDO \\ Universitat de Barcelona \\ Departamento de Filología Semítica. Área de Estudios Árabes e Islámicos \\ mdiazfajardo@ub.edu
}

Recibido: noviembre 2010

Aceptado: diciembre 2010

\section{RESUMEN}

Los periodos de tiempo cíclicos asociados con conceptos astronómicos fueron utilizados en la primera astrología islámica como indicadores de las influencias celestes. Este artículo explora las características de este género astrológico en el Magreb en los siglos XIII-XV.

Palabras clave: Magreb. Ciclos astrológicos. Técnica de prorrogación.

\begin{abstract}
Cyclic periods related to astronomical concepts had been used in early Islamic astrology as indicators of the celestial influences. This paper explores the features of this astrological genre in the Maghrib during the $13^{\text {th }}-15^{\text {th }}$ centuries.
\end{abstract}

Key words: Maghrib. Astrological cycles. Prorogation technique.

ÍNDICE: I. Antecedentes, II. El método de los astrólogos, 1. Fuentes, 1.1. Ibn al-Bannā’' (Marraquech, 1256-1321), 1.2. Ibn 'Azzūz (m. Constantina, 1354), 1.3. Al-Baqqār (fl. Fez, 1411-1418), 1.4. El copista-astrólogo anónimo (c. después de 1418), 2. Práctica, 3. Un método comprobado, 4. Procedencia, 5. Manifestaciones, 6. Los cuatro ciclos, 6.1. La qisma, 6.2. El dawr mayor, 6.3. El dawr medio, 6.4. El dawr menor, III. Conclusiones, IV. Traducción del texto de al-Baqqār, V. Edición del texto de al-Baqqār.

${ }^{1}$ Trabajo realizado dentro del proyecto de investigación "La evolución de la ciencia en la sociedad de al-Andalus desde la Alta Edad Media al pre-Renacimiento y su repercusión en las culturas europeas y árabes (siglos X-XV)" del MCI (FFI 2008-00234FILO). 


\section{ANTECEDENTES}

La astrología árabe medieval post-sasánida empleaba una serie de periodos de tiempo o ciclos para interpretar los sucesos del pasado (astrología histórica) o para prever la adversidad y la fortuna globales (astrología mundial). Ambos géneros se desarrollaron en colecciones de horóscopos ${ }^{2}$, como los que se encuentran en el Kitāb fì-l-qirānāt wa-l-adyān wa-l-milal ${ }^{3}$ de Māšā'allāh (m. c. 815) y en el Kitāb alkāmil ${ }^{4}$ de Ibn Nawbajt (entre 860-940), o bien en obras teóricas, como el Kitāb almilal wa-l-duwal ${ }^{5}$ y el Kitāb al-ulūf ${ }^{6}$ de Abū Ma'šar (c. 787- c. 886) y el Kitāb alazmina wa-1-duhūr ${ }^{7}$ del citado Ibn Nawbajt.

Abū Ma‘šar presenta, en el Kitāb al-ulūf, un sistema de pronosticación que se basa en tres conjuntos de ciclos divididos en cuatro categorías:

a) tasyīr o qisma: ciclo de 360.000 años (categoría suprema); 36.000 años (mayor); 3.600 años (media); 360 años (menor).

b) intihā': 12.000 años (suprema); 1.200 años (mayor); 120 años (media); 12 años (menor).

c) firdār: 30.240 años (suprema); 78 años (mayor); 675 años (media); 75 años (menor).

En el periodo de la qisma suprema se sucedieron tres conjunciones supremas de las posiciones medias de los siete planetas en Aries $0^{\circ}$ : al inicio del ciclo, cuando habían transcurrido 180.000 años y al final del ciclo ${ }^{8}$.

Ibn 'Azzūz, astrólogo magrebí del siglo XIV, explica' ${ }^{9}$ sobre la conjunción suprema: «el periodo más largo y el suceso más importante es la conjunción de los

${ }^{2}$ Sobre la historia astrológica de al-Battān̄̄ (m. 929), véase la obra póstuma de KENNEDY, Edward S., con la colaboración de van DALEN, Benno, SALIBA, George, y SAMSÓ, Julio. "AlBattānı̄'s Astrological History of the Prophet and the Early Caliphate". Suhayl, International Journal for the History of the Exact and Natural Sciences in Islamic Civilisation 9, (2009-2010), 13-148.

${ }^{3}$ KENNEDY, Edward S. y PINGREE, David. The Astrological History of Māshā'allāh. Cambridge-Massachussets: Harvard University Press, 1971.

${ }^{4}$ LABARTA, Ana. Mūsà ibn Nawbajt, al-Kitāb al-Kāmil, Horóscopos históricos, Edición y traducción, prólogo de Juan Vernet. Madrid-Bellaterra: Instituto Hispano-Árabe de Cultura, Universidad Autónoma de Barcelona, 1982; van BRUMMELEN, Glen. "The Astronomical System in Mūsā ibn Nawbakht's Astrological Treatise, The Kitāb al-KāmiP'. Centaurus 41, (1999), 213-243.

${ }_{5}^{5}$ YAMAMOTO, Keiji y BURNETT, Charles. Abü Ma ‘̌sar on Historical Astrology, The Book of Religions and Dynasties (On the Great Conjunctions), Volume One, The Arabic Original. BrillLeiden-Boston-Köln: Islamic Philosophy Theology and Science, 2000.

${ }^{6}$ PINGREE, David. The Thousands of $A b \bar{u}$ Ma 'shar. London: The Warburg Institute, University of London, 1968; KENNEDY, Edward S. "The World-Year Concept in Islamic Astrology", en D.A. King y M.H. Kennedy (eds.) [SIES:] Studies in the Islamic Exact Sciences. Beirut: American University of Beirut, 1983, 354-359; KENNEDY, Edward S. y van der WAERDEN, Bartel Leendert. "The World-Year of the Persians", en D.A. King y M.H. Kennedy (eds.) SIES. Beirut: American University of Beirut, 1983, 338-350.

${ }^{7}$ LABARTA, Ana y MESTRES, Àngel. Mūsà ibn Nawbajt, Kitāb al-azmina wa-l-duhūr, Tratado de astrología mundial. Valencia: Universidad de Valencia, 2005.

${ }^{8}$ PINGREE, David. The Thousands, 29.

${ }_{9}^{9}$ Manuscrito 1110 (fol. 65r) de la Biblioteca al-Hasaniyya de Rabat:

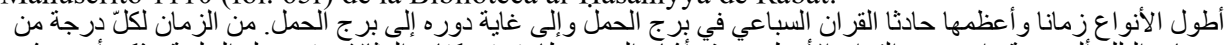

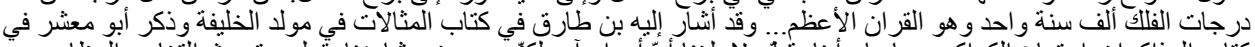

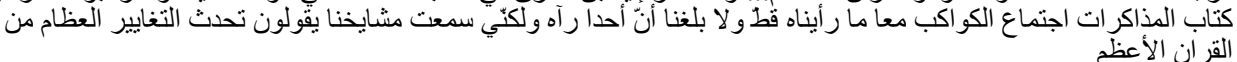


siete planetas en el signo de Aries hasta que completa su ciclo [360.000 años] cuando regresa al mismo signo; recorre un grado del círculo celeste en mil años [= 360.000 años $\left./ 360^{\circ}\right]$ : es la conjunción suprema... A ella aludió Ibn Țāriq en el Kitāb al-Mitāāāt fì mawlid al-jalīfa $a^{10}$ y Abū Ma šar mencionó en el Kitāb al-Mudākarāt. la conjunción de todos los planetas aún no la hemos visto ni sabemos que alguien la haya visto pero escuché a nuestros mayores decir que los cambios importantes suceden a causa de la conjunción suprema ${ }^{11} \gg$.

La qisma suprema es el ciclo origen denominado «el año del mundo» y contiene al resto de los ciclos de los grupos qisma e intihā': en el grupo de las qisma, la categoría mayor realiza 10 revoluciones en una qisma suprema; la media, 100 revoluciones; y la menor, 1.000 revoluciones. En las intihā', la categoría suprema realiza 30 revoluciones en una qisma suprema; la intiha $\bar{a}$ mayor realiza 300 revoluciones; la media, 3.000 revoluciones; y la categoría menor $30.000^{12}$. El tercer grupo del sistema de Abū Ma“šar está relacionado con las firdār de los planetas, ciclos creados por periodos de tiempo en los que ejerce su influencia un planeta, un nodo, un signo zodiacal o una combinación de un planeta y un signo.

En el horóscopo se reflejan las posiciones distintas que alcanzan cada uno de los ciclos, desde el inicio de su rotación en Aries $0^{\circ}$ al inicio de la qisma suprema, en función de su velocidad y según la fecha para la que se levante el horóscopo, de este modo se obtienen múltiples indicadores celestes.

El sistema de ciclos de Abū Ma'šar ${ }^{13}$ se encuentra en otras doce fuentes orientales, la última de ellas del siglo XV. Ibn Nawbajt mantiene los grupos de Abū $\mathrm{Ma}$ ‘šar con algunas variaciones, las más significativas son la ausencia de las

${ }^{10}$ Obra citada por Abū Sa‘īd Šādān (fl. siglo IX) en su obra Mud̄ākarāt Abū Ma ‘̌ary por Șā‘id alAndalusī (fl. Toledo, 1029-1070) en sus Tabaqāt al-umam. En las Tabaqāt se lee al-Maqālāt de Ya'qūb ibn Țāriq [fl. Bagdad, 2 ${ }^{\mathrm{a}}$ mitad del siglo VIII] obra sobre horóscopos de nacimientos de califas

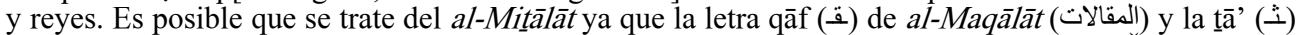
de al-Mitāāāt (المثنالات) se pueden confundir en árabe manuscrito. Para Abū Sa'īd Šādān, véase SEZGIN, Fuat. [GAS:] Geschichte des Arabischen Schrifttums, VII, Astrologie, Meteorologie und Verwandtes. Leiden: E. J. Brill, 1979, 16; para Șā'id al-Andalusī, véase, BŪ 'ALWĀN, Hayāt. TTabaqāt al-umam, ta'līf: Șā'id al-Andalusī, taḥqīq: Hayāt Bū 'Alwān. Beirut: Dār al-țalī'a li-l-țabā'a wa-1-našr, 1985, 151; BLACHÈRE, Régis. Șā‘id al-Andalusī, Kitāb Tabaqāt al-Umam (Livre des Catégories des Nations), traduction avec notes et indices précédée d'une introduction. Paris: Publications de l'Institut des Hautes Études Marocaines, 1935, 117; MAÍlLLO SALGADO, Felipe. Șā'id al-Andalusī, Libro de las categorías de las naciones (Kitāb Tabaqāt al-Umam), Estudio y traducción. Madrid: Akal Universitaria, 1999, 115; LLAVERO RUÍZ, Eloísa (traducción, notas e índices) y MARTÍNEZ LORCA, Andrés (introducción y notas). Historia de la filosofia y de las ciencias o Libro de las categorías de las naciones, (Kitāb Tabaqāt al-umam), Șā'id al-Andalusî. Madrid: Editorial Trotta, 2000, 135.

${ }^{11}$ En la versión latina de al-Mud̄ākarāt llamada Albumasar in Sadan aparece la cita que menciona Ibn 'Azzūz con alguna variante: «Returning to the theme of great conjunctions, Albumasar said that he had never seen one nor met anyone who had, but that he had heard old sages say that it produced great kings»", traducción de THORNDIKE, Lynn. "Albumasar in Sadan”. Isis 45 1, (1954), 24-25.

${ }^{12}$ PINGREE, David. The Thousands, 59-60.

${ }^{13}$ Sobre la adscripción de estos ciclos a la tradición india, véase PINGREE, David. The Thousands, 29-31; PINGREE, David. "The Liber Universus of 'Umar Ibn al-Farrukhān al-Ṭabarī”. Journal for the History of Arabic Science vol. $1 \mathrm{n}^{\circ}$ 1, (1977), 8-12. Sobre su relación con fuentes sasánidas, véase van der WAERDEN, Bartel Leendert. "The Astronomical System of the Persian Tables II”. Centaurus vol. 30 number 3, (1987), 197-211. 
categorías supremas en las qisma y las firdāry el inicio de la rotación de la mayoría de los ciclos en la fecha del diluvio universal, que Abū Ma šar data ${ }^{14}$ el 17 de febrero de -3101 , coincidiendo con una conjunción media de todos los planetas en Aries $0^{\circ}$ a mediados del periodo de la qisma suprema.

Una referencia a los ciclos orientales se encuentra en al-Andalus (primera mitad del siglo X) en la revisión de la traducción del tratado's de 'Umar ibn al-Farrujān alTabarī en la que se alude a un horóscopo levantado el año 940 para la latitud de Córdoba y al inicio de un nuevo ciclo del firdār supremo ${ }^{16}$.

En este trabajo analizo la herencia astrológica de los ciclos en el occidente islámico a través de varias fuentes magrebíes que transmiten el método de los astrólogos.

\section{EL MÉTODO DE LOS ASTRÓLOGOS}

Es un sistema de cuatro ciclos (véase el comentario en la sección seis). El orden siguiente sigue la exposición de Ibn al-Bannā', la fuente más antigua:

1. El dawr menor (al-dawr al-asggar): ciclo de doce años, también llamado burŷ al-muntaḥà / al-tasyīr al-dawrī / burŷ al-intihā' / burŷ al-dawr.

2. El dawr medio (al-dawr al-awsat): ciclo de setenta y dos o setenta y cinco años. Otra denominación que recibe es al-tasyīr al-firdārī.

3. El dawr mayor (al-dawr al-akbar): ciclo de ciento veinte años, conocido por al-tasyīr al-tabī $\bar{x}$.

4. La qisma: ciclo de trescientos sesenta años, denominado también daraŷat al-āhāad.

Se encuentra en el Magreb desde finales del siglo XIII hasta con posterioridad a la primera mitad del siglo XV y es calificado como «el método de la comunidad de los astrólogos» (madhab ŷamā‘at al-munaŷŷimīn).

\section{FUENTES}

\subsection{IBN AL-BANNĀ' (MARRAQUECH, 1256-1321)}

Incorpora el método de los astrólogos (de aquí en adelante, el Método) en una obra breve que ha sido editada por A. Ŷabbār y M. Aballāg ${ }^{17}$ y denominada por éstos al-Kalām 'alà-1-tasyiràt wa-mațārịh al-šu 'à'ăt (Exposición sobre prorrogaciones y proyecciones de rayos) adoptando por título las palabras con las que Ibn al-Bannā̄ finaliza. Ibn al-Bannā' expone el método de forma teorizante en las páginas 162-163.

\footnotetext{
${ }^{14}$ PINGREE, David. “Astronomy and Astrology in India and Iran”. ISIS 54 parte 2 nº 176, (1963), 243.

${ }^{15}$ PINGREE, David. "The Liber Universus".

${ }^{16}$ En la península, hay una muestra de astrología histórica con Meguillat ha-megalleh, obra de Abraham Bar Hiyya escrita en hebreo entre 1120 y 1129, véase, MILLÀS i VALLICROSA, Josep María. Abraam Bar Hiia, Llibre Revelador, Meguil.lat Hamegal.lè, segons l'edició del text revisat i prologat pel Dr. Juli Guttmann, versió de l'hebreu per J. Millàs $i$ Vallicrosa. Barcelona: Editorial Alpha, 1929.

${ }^{17} \hat{Y}$ ABBĀR, Ahmmad y ABALLĀG, Muhammad. Hayāt wa-mu'allafăt Ibn al-Bannā' al-Murrākušī ma'a nuṣūṣ gayr manšüra. Casablanca: Publications de la Faculté des Lettres-Rabat, 2001, 160-165.
} 


\subsection{IBN ‘AZZŪZ (M. CONSTANTINA, 1354)}

Transmite el Método (folios 124r-124v) en el capítulo quinto, «Conocimiento de la prorrogación, lo que indicaron sobre ella, y las proyecciones de rayos», de la parte segunda de su obra Kitāb al-fusuūl fì ŷam 'al-uṣūl conservada en la Biblioteca al-Hasaniyya de Rabat ${ }^{18}$ (manuscrito número 1110).

Ibn 'Azzūz sigue el mismo orden expositivo que Ibn al-Bannā' y ambos astrólogos coinciden en el periodo de tiempo del dawr medio (setenta y dos años). Sin embargo, Ibn 'Azzūz no repite las mismas omisiones y da una lectura diferente de varios términos y nociones astrológicas (el dawr mayor tiene la equivalencia para un mes de $0 ; 25^{\circ}$ en el texto de Ibn al-Bannā', mientras que el texto de Ibn 'Azzūz presenta la equivalencia correcta de $0 ; 15^{\circ}$ ). Estas variantes podrían deberse a un copista más atento o al propio Ibn 'Azzūz. El ejemplo más significativo es la lectura divergente que presenta el párrafo siguiente: de acuerdo con Ibn 'Azzūz' «Se obtienen de estas prorrogaciones, desde el grado del ascendente y de cualquier indicador que fuera, con los ciclos reglamentados, las posiciones deseadas y temidas»; mientras que en Ibn al-Bannā’ se encuentra el párrafo, probablemente, corrupto $^{20}$ : «Se obtiene, entre estas dos prorrogaciones, el grado del ascendente o cualquier indicador que fuera. La ordenación del cuadrante que es la cuadratura de las clases de los siete planetas a través de uno de los aspectos mencionados». Las diferencias entre ambos textos sugieren que Ibn 'Azzūz tuvo acceso al Método a través de otra fuente y no mediante la obra de Ibn al-Bannā' ${ }^{21}$.

El relato de Ibn 'Azzūz es cualitativo, tal y como ocurría en Ibn al-Bannā', pero en el epílogo de su obra hay varios ejemplos prácticos del Método, una serie de horóscopos ${ }^{22}$ en los que utiliza los cuatro ciclos.

\subsection{AL-BAQQĀR (FL. FEZ, 1411-1418)}

Explica el Método en el capítulo primero, «Conocimiento de las clases de prorrogaciones características de los natalicios», de la parte quinta de su obra alAdwār fì tasyīr al-anwār que nos ha llegado completa en tres manuscritos: el 916 (el

${ }^{18}$ Al-JATTṬĀBĪ, Muhammad al-'Arabī. Catalogues of the Al-Hassania Library, volume III, Manuscripts of Mathematics, Astronomy, Astrology and Geography. Rabat: al-Ma'ārif al-Ŷadīda, 1983, 367-368.

${ }^{19}$ Manuscrito 1110 (fol. 124v) de la Biblioteca al-Hasaniyya de Rabat:

$$
\text { وألمخوفة من هذه [في المخطوط: هذا] التسييرات درجة الطالع وأيّ دليل كان في الأدوار المرتبة على المو اضع المرجوّة }
$$

${ }^{20} \hat{Y}$ ABBĀR, Ahmad y ABALLĀG, Muhammad. Hayāt wa-mu'allafăt, 163:

فيحصل بين هذا التسييرين درجة الطالع أو أبيّ دليل كان فمرتبة الربع الذي هو تربيع أنو اع الكو اكب السبعة من إحدى المناظر

${ }^{21}$ Algo lógico, si tenemos en cuenta que el texto de Ibn al-Bannā’ pertenece a su primera etapa en la que se interesó por la astrología y de la que se conservan varios textos cortos que parecen notas de estudio, entre ellos al-Kalām (véase la sección 2).

${ }_{22}$ Estudiados por SAMSÓ, Julio. "Horoscopes and History: Ibn 'Azzūz and his retrospective horoscopes related to the battle of El Salado (1340)", en L. Nauta and A. Vanderjagt (eds.) Between Demonstration and Imagination: Essays in the History of Science and Philosophy Presented to John D. North. Leiden-Boston-Köln: Brill, 1999, 101-124 (reimpresión en SAMSO, Julio. Astronomy and Astrology in al-Andalus and the Maghrib. Aldershot: Ashgate-Variorum, 2007, $\mathrm{n}^{\circ} \mathrm{X}$ ). 
Método se encuentra en los folios 259v-261v) de la Biblioteca de El Escorial ${ }^{23}$ y el 826 (fols. 108v-110r) y el 5372 (págs. 43-47) de la Biblioteca al-Hasaniyya de Rabat ${ }^{24}$.

Al-Baqqār desarrolla la exposición del Método mediante el cálculo y la tabla propios de cada uno de los cuatro ciclos. Es por este motivo que he escogido el texto de al-Baqqār para la traducción y edición en la secciones IV y V respectivamente.

Al-Baqqār expone los ciclos en orden inverso: comienza por (1) la qisma, (2) el dawr mayor, (3) el dawr medio y finaliza con (4) el dawr menor. A las dos variantes de Ibn al-Bannā' e Ibn 'Azzūz de un mismo párrafo corrupto (mencionado en la sección 1.2), el texto de al-Baqqār da una tercera lección: «Se logra de estas prorrogaciones, del grado del ascendente o de cualquier indicador que fuera que pase, en el cuadrante en el que se encuentre, por todas las luces de los siete planetas a través de alguno de los aspectos mencionados» (véase la edición en la sección $\mathrm{V}$, [7]).

Esta divergencia en la forma junto a varias lecturas diferentes señalan que el Método habría llegado a las tres fuentes estudiadas (Ibn al-Bannā', Ibn 'Azzūz y alBaqqār) por vías distintas.

\subsection{El COPISTA-ASTRÓLOGO ANÓNIMO (C. DESPUÉS DE 1418)}

Añade el Método en los márgenes (fols. 104r-105r) del capítulo «Sobre la prorrogación» del manuscrito 3503 de la Biblioteca al-Hasaniyya de Rabat ${ }^{25}$ que contiene la obra de Ibn Abī-l-Riŷāl Kitāb al-bāri ' fì ạ̣kām al-nuŷūm. El copista cita a al-Baqqār en relación con el Método y el orden en su exposición sigue el del texto de al-Baqqār por lo que, probablemente, trasladó el Método de este último lo que permite situar al copista después del año 1418, fecha hacia la que al-Baqqār compuso $^{26}$ el al-Adwār fì tasyīr al-anwār.

\section{PRÁCTICA}

Hemos visto en la sección anterior que el Método se incluye en libros y/o capítulos que tratan de la prorrogación (tasyīr), procedimiento en el que participan las fracciones de los ciclos (sus equivalencias entre grados y años, meses o días, véase la sección 6) y que pretende (a) establecer la fecha de un suceso o (b) determinar un indicador con el que interpretar las influencias celestes.

En el primer supuesto (a), se calcula la distancia en grados ecuatoriales entre dos indicadores celestes, el primero de ellos es un indicador relacionado con el sujeto del horóscopo, como el ascendente, y el segundo, un indicador de naturaleza maléfica capaz de cortar el avance del primero. La cantidad resultante de grados ecuatoriales se expresa en tiempo mediante las fracciones del ciclo de la qisma. Ibn 'Azzūz da la

${ }^{23}$ DERENBOURG, Hartwig y RÉNAUD, H.P.J. Les Manuscrits Arabes de I'Escurial, tome II, fascicule 3. Paris: Publications de l'École Nationale des Langues Orientales Vivantes, 1941, 16.

${ }^{24}$ Al-JATTṬĀB̄̄, Muhammad al-'Arbī. Catalogues, 430-431.

${ }^{25}$ Al-JAṬṬ̂̄B İ, Muhammad al-'Arbì. Catalogues, 440-441.

${ }^{26}$ DÍAZ-FAJARDO, Montse. La teoría de la trepidación en un astrónomo marroquí del siglo $X \mathrm{~V}$. Estudio y edición crítica del Kitāb al-adwār fì tasyīr al-anwār (parte primera) de Abū 'Abd Allāh alBaqqār. Barcelona: Anuari de Filologia (Universitat de Barcelona) XXIII, B4. Instituto "Millás Vallicrosa" de Historia de la Ciencia Árabe, 2001, 19. 
definición siguiente de la prorrogación y su relación con los ciclos: «Significado de la prorrogación: es la determinación de la medida del arco de la distancia entre los dos indicadores, el indicador que se prorroga y el indicador al que se dirige la prorrogación, a través de aplicar los ciclos que regulan el arco de la prorrogación ${ }^{27}$.

En el segundo supuesto (b), se calcula el punto de la eclíptica que alcanza un indicador celeste, transcurrido cierto número de años. El avance del indicador, que al igual que en el caso anterior estará relacionado con el sujeto del horóscopo, se realiza en grados eclípticos mediante las fracciones de los ciclos del dawr mayor, el dawr medio y/o el dawr menor.

El trabajo astrológico se ha distribuido ${ }^{28}$ en las categorías siguientes: 1) astrología genetlíaca, 2) elecciones e interrogaciones, 3) ciclos, 4) proyección de rayos, prorrogación y otras técnicas. El Método es un ejemplo de la conexión entre las diferentes áreas de la astrología: es un procedimiento de prorrogación que se sirve de un sistema de ciclos y se emplea en la astrología genetlíaca.

La permanencia del Método durante tres siglos y las variantes entre los textos de Ibn al-Bannā', Ibn 'Azzūz y al-Baqqār sugieren que fue un sistema con una difusión notable en el Magreb. Su denominación, que lo identifica con el gremio de astrólogos (madhab yamā'at al-munaŷŷimīn), y su adición en la obra de Ibn Abī-lRiŷāl como notación al margen señalan que debió de ser muy popular. ¿Cuáles eran los motivos para esta aceptación?, ¿formaba parte del currículo que se le exigía al astrónomo o respondía al ejercicio de la profesión astrológica?: en el caso de Ibn alBannā' pudo ser parte de su formación ya que el Método se encuentra junto a otros tratados astrológicos muy breves que, probablemente, eran unos meros apuntes de estudiante ${ }^{29}$. No obstante, se cree que Ibn al-Bannā' practicó la astrología prediciendo acertadamente la muerte del sultán meriní Abū Sa‘īid (reinó 1309-1331), suceso que se solía pronosticar mediante la prorrogación y los ciclos. Las motivaciones de Ibn 'Azzūz y al-Baqqār pudieron ser prácticas.

El primero utilizó los tres dawr (el dawr mayor, medio y menor) en los horóscopos que levantó de un suceso histórico, la batalla de El Salado ${ }^{30}$ (1340) quizá con la intención de encontrar las razones astrológicas que llevaron al sultán meriní de Fez Abū-l-Hasan a la derrota ante el rey de Castilla Alfonso XI.

Los ciclos astrológicos y su asociación con la prorrogación constituyen una doctrina astrológica compleja. Muchos de los métodos de prorrogación requieren un buen conocimiento matemático y siguen procedimientos con normas astronómicas

${ }^{27}$ Manuscrito 1110 (fol. 122r) de la Biblioteca al-Hasaniyya de Rabat:

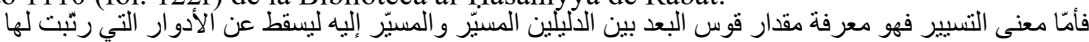

${ }^{28}$ NALLINO, Carlo Alfonso. "Astrology", en M. Th. Houtsma, T. W. Arnold, R. Basset and R. Hartmann (eds.) First Encyclopaedia of Islam 1913-1936 I. Leiden, New York, Kobenhaun, Köln: E. J. Brill, 1987, 496; SALIBA, George. "Astrology/Astronomy, Islamic", en P. Chelkowski y J. Claster (eds.) A History of Arabic Astronomy. Planetary Theories during the Golden Age of Islam. New York and London: New York University Press, 1994, 70-72.

${ }_{29}^{2} \hat{Y}$ ABBĀR, Aḥmad y ABALLĀG, Muhammad. Hayāt wa-mu'allafăt., 40-45, 52-63, 83-84; SAMSÓ, Julio. "Ibn al-Bannā': Abū al-'Abbās Aḥmad ibn Muhammad ibn 'Uthmān al-Azdī alMarrākush̄̄”, en T. Hockey et al. (eds.) The Biographical Encyclopedia of Astronomers. New York: Springer, 2007, 551-552.

${ }^{30}$ SAMSÓ, Julio. "Horoscopes and History". 
precisas. La técnica de la prorrogación está ligada a los sistemas de ciclos y sus fracciones que enlazan con las tradiciones astrológicas más antiguas. Al-Baqqār ilustra matemáticamente el Método con el cálculo de la prorrogación y las tablas que listan las equivalencias entre grados y tiempo para cada ciclo. Así su texto se convierte en un manual astrológico completo. Al mismo tiempo, los astrólogos practicantes que ignoraban la teoría subyacente pero conocían el procedimiento a seguir, para lo que se ayudaban de tablas y/o instrumentos ${ }^{31}$, encontrarían muy útiles las tablas de al-Baqqār.

\section{UN MÉTODO COMPROBADO}

El párrafo [3] del texto (véase las secciones IV y V) refiere que el Método se distingue, entre los otros muchos procedimientos de prorrogación, por estar validado por la experiencia (al-taŷriba), el examen (al-imtiḥān), la analogía racional (al-qiyās al-'aqlì) y la ley física (al-qānūn al-tabīisì).

De acuerdo con el estudio de Ch. Burnett ${ }^{32}$, es posible identificar varias corrientes para verificar la verdad de las afirmaciones astrológicas en la tradición árabe antigua. En los siglos VIII, con 'Umar ibn al-Farrujān, y IX, con al-Kindī, las teorías astrológicas reciben su validez de las demostraciones/experiencia sensible (al-barāhīn) y el silogismo/analogía (al-qiyās al- 'aqlī̄). En el mismo siglo IX, Abū Ma‘šar sigue otra tendencia en la que lo más significativo es la exclusión de las demostraciones/experiencia sensible (al-barāhīn). En el siglo XI, Kūšyār ibn Labbān es más claro y, adoptando lo determinado por Ptolomeo en el Tetrabiblos, cree que la astronomía establece sus teorías mediante demostraciones (al-barāhīn) geométricas y la astrología, mediante la experiencia (al-taŷriba) y la analogía (al-qiyās).

De lo anterior, se puede entender que el Método se ajusta a las reglas de la astrología según la opinión de Abū Ma‘šar y, sobre todo, de Kūšyār ibn Labbān. Esta es la línea que sigue al-Baqqār en otro de sus trabajos sobre astro-meteorología: «Los astrólogos (aṣhāb al-aḥkām) consideran que los cuerpos celestes ofrecen indicios (dalālât) que han llegado a conocer gracias a experiencias (taŷârib) y analogías $(\text { qiyāsāat) }\rangle^{33}$.

La serie de horóscopos de Ibn 'Azzūz sobre la batalla de El Salado ${ }^{34}$ se levantaron cuando ya se había producido el acontecimiento, es decir que Ibn 'Azzūz conocía los hechos y podía comprobar el resultado del sistema de prorrogación y

${ }^{31}$ Este es uno de los tipos de astrólogos de la corte que clasifica al-Qabīṣī (fl. siglo X): «The fourth kind are those who rely entirely on instruments. These know nothing about astrological theory and practice», traducción de BURNETT, Charles, YAMAMOTO, Keiji y YANO, Michio. Al-Qabīṣ̄ (Alcabitius): The Introduction to Astrology. London-Turin: Warburg Institute Studies and Texts, 2004, 6. Es probable que se diera el mismo tipo de astrólogos usuarios en tiempos de al-Baqqār.

${ }^{32}$ BURNETT, Charles. "The Certitude of Astrology: The Scientific Methodology of al-Qabīṣ̄ and Abū Ma'shar". Early Science and Medicine 7, (2002), 198-213.

${ }^{33}$ Traducción de GUESMI, Chedli. El Kitāb al-amțār wa'l-as'ār de Abū 'Abd Allāh al-Baqqār. Edición crítica y estudio. Barcelona: Universitat de Barcelona, 2005, sección 6.

${ }^{34}$ SAMSÓ, Julio. "Andalusian Astronomy in 14th Century Fez: al-Zīj al-Muwāfiq of Ibn 'Azzūz al-Qusanțīn̄”. Zeitschrift für Geschichte der Arabisch-Islamischen Wissenschaften 11, (1997), 77-79; SAMSÓ, Julio. "Horoscopes and History", 101-102. 
ciclos que utilizaba, algo que puede constituir un ejemplo de comparación y control con la práctica experimental ${ }^{35}$. En la sección I, hemos visto que Abū Ma‘šar tiene que recurrir a la tradición para defender el uso de la conjunción suprema/qisma suprema: su periodo de tiempo es demasiado grande para que las influencias derivadas de ella pudieran ser verificadas, mientras que la duración menor de los ciclos del Método permitía su examen.

\section{PROCEDENCIA}

Los cuatro ciclos del Método se corresponden con las divisiones menores del sistema de Abū Ma‘šar:

- Sistema de Abū Ma“šar: tasyīr qisma menor (ciclo de 360 años); intihā' medio (ciclo de 120 años); firdār menor (ciclo de 75 años); intihà' menor (ciclo de 12 años).

- El Método: qisma (ciclo de 360 años); dawr mayor (ciclo de 120 años); dawr medio (ciclo de 75 /72 años); dawr menor (ciclo de 12 años).

El Método podría ser una derivación del sistema de Abū Ma‘šar (a pesar de no estar documentado en fuentes anteriores al siglo XIII) y es probable que se conociera en Oriente en ese tiempo ya que varios astrólogos orientales próximos a Abū Ma‘šar utilizan las fracciones de los ciclos del Método para la prorrogación (véase la sección 6 y siguientes).

\section{MANIFESTACIONES}

Una representación de los ciclos y sus fracciones relacionados con la prorrogación aparece en al-Andalus (siglo XI) con el sistema de al-Istiŷy $\overline{1}^{36}$ llamado «las cuatro categorías de números» ${ }^{37}$, en alusión a los números de años de equivalencia con 1 signo zodiacal. Las categorías se establecen de acuerdo con el periodo de tiempo que más se adecua a determinado suceso y a partir de la influencia de los doce signos zodiacales sobre el hombre:

\footnotetext{
${ }^{35}$ Sobre este sistema de trabajo en al-Istiŷ̄ (fl. Toledo y Cuenca, segunda mitad del siglo XI) e Ibn Qunfud (Constantina, 1339-1407), véase SAMSÓ, Julio y BERRANI, Hamid. "World Astrology in Eleventh-Century al-Andalus: The Epistle on Tasyīr and the Projection of Rays by al-Istijī". Journal of Islamic Studies 10:3, (1999), 307-309 (reimpresión en SAMSO, Julio. Astronomy and Astrology, $\mathrm{n}^{\mathrm{o}}$ V); SAMSÓ, Julio. "Cuatro horóscopos sobre muertes violentas en al-Andalus y el Magrib", en M. Fierro (eds.) De muerte violenta. Política, religión y violencia en al-Andalus. Estudios onomásticobiográficos de al-Andalus. XIV. Madrid: Consejo Superior de Investigaciones Científicas, 2004, 500 (reimpresión en Astrometeorología y Astrología Medievales. Barcelona: Publicacions i Edicions de la Universitat de Barcelona, 2008, $\mathrm{n}^{\circ}$ XIII); SAMSÓ, Julio y BERRANI, Hamid. "The Epistle on Tasyirr and the projection of rays by Abū Marwān al-Istijī”. Suhayl. Journal for the History of the Exact and Natural Sciences in Islamic Civilisation 5, (2005), 179-180 (reimpresión en Astrometeorología y Astrología, n $\mathrm{n}^{\circ} \mathrm{XIV}$ ). Véase también el párrafo [22] en la sección IV de este artículo.

${ }^{36}$ SAMSÓ, Julio y BERRANI, Hamid. "World Astrology"; SAMSÓ, Julio y BERRANI, Hamid. "The Epistle".

${ }^{37}$ SAMSO, Julio y BERRANI, Hamid. "The Epistle”, 183-185.
} 
a. Los miles (ciclo de 12.000 años en el que 1 signo $=1.000$ años). Indicaciones sobre el mundo. Ciclos: (1) tasyīr de 12.000 años, (2) tasyīr de la conjunción mayor ${ }^{38}$ y (3) burŷ al-intihā'.

b. Las centenas (ciclo de 1.200 años en el que 1 signo $=100$ años). Indicaciones sobre religiones y estados. Ciclos: (1) tasyīr de 1.200 años, (2) tasyīr de la conjunción media y (3) burŷ al-intihă .

c. Las decenas (ciclo de 120 años en el que 1 signo $=10$ años). Indicaciones sobre el hombre. Ciclos: (1) tasyīr de 120 años, (2) al-firdārīy (3) burŷ al-intihā'.

d. Las unidades (ciclo de 12 años en el que 1 signo $=1$ año). Indicaciones sobre aniversarios y gobiernos de reyes. Ciclos: (1) tasyīr de la conjunción de los 60, (2) tasyīr de la conjunción menor y (3) burŷ al-intihāa

Tres de los cuatro ciclos que componen el Método son los utilizados por alIstiŷi para obtener indicaciones relacionadas con el hombre:

- Categoría de las decenas en el sistema de al-Istiŷĩ: (carece del ciclo de 360 años); tasyīr de 120 años (ciclo de 120 años); al-firdārī (ciclo de 75 años); burŷy al-intihā' (ciclo de 12 años).

- El Método: qisma (ciclo de 360 años); dawr mayor (ciclo de 120 años); dawr medio (ciclo de 75 /72 años); dawr menor (ciclo de 12 años).

\section{LOS CUATRO CICLOS}

\subsection{LA QISMA: [5]-[9] $]^{39}$}

[6]. Es un ciclo de 360 años $\left(360^{\circ} / 1^{\circ}\right)$ en el que 1 año es igual a $1^{\circ} ; 1$ mes equivale a $0 ; 5^{\circ}$ y 1 día es igual a $0 ; 0,10^{\circ}$.

El resultado de la prorrogación sobre el círculo del ecuador se expresaba en tiempo con la equivalencia de la qisma, 1 año igual a 1 grado $\left(360^{\circ} / 360\right.$ años $\left.=1^{\circ}\right)$. Se conocen seis métodos utilizados con esta fracción. Uno de los más empleados fue, probablemente, el método de la línea horaria ${ }^{40}$ que procede de Ptolomeo y está documentado en trece fuentes islámicas entre los siglos X al XV: al-Battān̄i, Ibn Hibintā, al-Qabīṣī, Kūšyār ibn Labbān, al-Bīrūn̄̄, Ibn al-Zarqālluh, Abraham ibn Ezra, los libros alfonsíes «Libro dell ataçir» y «Libro de las armellas», Husayn ibn Bāṣo, Ibn al-Bannā’, Aḥmad ibn Ḥusayn ibn Bāṣo y al-Baqqār. En la fórmula del método de la línea horaria intervienen las ascensiones $(\alpha)$ (que serán rectas $\left(\alpha_{0}\right) \mathrm{u}$

${ }^{38}$ En los periodos de las conjunciones las equivalencias en tiempo se obtienen de dividir $360^{\circ}$ entre el tiempo en el que el ciclo de la conjunción se cumple. Por ejemplo, en el tasyīr de la conjunción de los sesenta 1 año $=6^{\circ}$ ya que $360^{\circ} / 60$ años $=6^{\circ}$.

${ }^{39}$ En esta sección y las siguientes, los números entre corchetes hacen referencia a los párrafos que se comentan de la traducción (sección IV) y la edición (sección V).

${ }^{40}$ HOGENDIJK, Jan P. "Progressions, Rays and Houses in Medieval Islamic Astrology: A Mathematical Classification", trabajo inédito presentado en el simposio organizado por el Dibner Institute sobre New Perspectives on Science in Medieval Islam. Cambridge-Mass., del 6 al 8 de noviembre, (1998); DÍAZ-FAJARDO, Montse. "Métodos de prorrogación relacionados con la proyección de rayos: la prorrogación de la qisma en la obra de al-Baqqār de Fez". Archives Internationales d'Histoire des Sciences, 60/2-165, (2010), 13-42. 
oblicuas $\left(\alpha_{\varphi}\right)$ dependiendo de la cúspide en la que se encuentre el indicador), la longitud $(\lambda)$ de los dos indicadores $\left(\mathrm{d}_{1} \mathrm{y} \mathrm{d}_{2}\right)$ y de la cúspide celeste (c) así como las horas temporales (ht):

$$
\underset{\left[\alpha_{0}\left(\lambda \mathrm{d}_{2}\right)-\alpha_{0}\left(\lambda \mathrm{d}_{1}\right)\right] \pm \frac{\left[\alpha_{\varphi}\left(\lambda \mathrm{d}_{2}\right)-\alpha_{\varphi}\left(\lambda \mathrm{d}_{1}\right)\right]-\left[\alpha_{0}\left(\lambda \mathrm{d}_{2}\right)-\alpha_{0}\left(\lambda \mathrm{d}_{1}\right)\right] \mid}{6}}{\operatorname{lht}\left(\lambda \mathrm{d}_{1}\right)} \times \frac{\left|\alpha\left(\lambda \mathrm{d}_{1}\right)-\alpha\left(\lambda_{\mathrm{C}}\right)\right|}{6}
$$

\subsection{EL DAWR MAYOR: [10]-[18]}

[11]. Es un ciclo de 120 años $\left(360^{\circ} / 3^{\circ}\right)$ en el que 1 año equivale a $3^{\circ} ; 1$ mes es igual a $0 ; 15^{\circ}$ y 1 día, a $0 ; 0,30^{\circ}$.

[15]. La fracción de este ciclo se utiliza en la prorrogación sobre el círculo de la eclíptica. Su cálculo es una proporción simple en la que, conocidos los grados que corresponden a un año, sabremos los grados que corresponderán a un número $n$ de años que, sumados a la longitud del indicador del horóscopo determinarán su posición en la eclíptica llamada término (intihā) de la prorrogación. Este método, la progresión sobre la eclíptica, es el único que se conoce $^{41}$ para los tres tipos de dawr (mayor, medio y menor). Es característico de los astrólogos islámicos occidentales.

[10]; [12]; [13]. De acuerdo con el texto, el nombre que recibe esta clase segunda, dawr mayor o prorrogación natural (al-tasyīr al-tabí $\mathfrak{i})$ característica del género humano, se debe a que su periodo de 120 años se adecua a la duración de la vida humana que se sitúa entre los sesenta y los ochenta años. Esto se explica porque, si consideramos que el indicador se encuentra en la casa I y que las casas miden aproximadamente $30^{\circ}$, la posición del indicador, transcurrido $n$ años, con el método de la progresión sobre la eclíptica será:

- Transcurridos 60 años: $60 \times 3^{\circ}=180^{\circ}$

Término de la prorrogación $=\lambda_{\text {casa I }}+180^{\circ}=$ casa VII

- Transcurridos 70 años: $70 \times 3^{\circ}=210^{\circ}$

Término de la prorrogación $=\lambda_{\text {casa I }}+210^{\circ}=$ casa VIII

- Transcurridos 80 años: $80 \times 3^{\circ}=240^{\circ}$

Término de la prorrogación $=\lambda_{\text {casa I }}+240^{\circ}=$ casa IX

El indicador se encuentra al cabo de sesenta años en la casa VII y al cabo de setenta, en la casa VIII. De acuerdo con el párrafo [13], el significado astrológico de la casa VII es el contrario al del ascendente [casa que se relaciona con la vida] y la casa VIII significa los bienes, la muerte y lo efímero. De acuerdo con al-Bīrūnī ${ }^{42}$,

${ }^{41}$ De acuerdo con al-Baqqār (al-Adwār, parte IV, capítulo 4; ms. H8, fol. 103r; ms. H5, pág. 33; ms. E, fol. 254r), Abū Ma šar prorrogaba la qisma con grados eclípticos en su Kitāb al-ulūf (obra que no se ha conservado). No sabemos si esto significa que existía un segundo método de prorrogación sobre el círculo de la eclíptica.

${ }^{42}$ En al-Tafhīm (traducción de RAMSAY WRIGHT, Robert. Kitāb al-tafhīm li-awā'il șinā'at altanŷīm. Tașnīf Abī-l-Rayhān Muhammad ibn Ahmad al-Bīrūnī. The Translation facing the Text. London: Luzac \& Co, 1934, 275 y 278). 
las casas VII, VIII y IX carecen de cuerpo y alma porque en este grupo de tres casas se encuentran la casa de la muerte (la VIII) y la del viaje (la IX).

[14]. En la astrología oriental, sólo conocemos el uso de la progresión sobre la eclíptica con la fracción del dawr mayor $\left(1\right.$ año $=3^{\circ}$ ) en el Kitāb sarā'ir al-hikma fì 'ilm al-nuŷūm de al-Hamdān̄̄is (Yemen, c. 893-c. 951). Entre los astrólogos occidentales fue utilizado por al-Istiŷ̄în ${ }^{44}$ además de Ibn al-Bannā', Ibn 'Azzūz y al-Baqqār.

[16]. Al-Baqqār realiza un cálculo sencillo para conocer la fecha del suceso: toma de la tabla la equivalencia en tiempo de la fracción menor de tres grados del resultado de la prorrogación y lo suma a la fecha del aniversario.

[17]-[18]. Al-Baqqār obtiene el término de la prorrogación y la fecha del suceso con la tabla. Estos procedimientos se obtuvieron mediante el cálculo en [15] y [16].

\subsection{EL DAWR MEDIO: [19]-[26]}

[20]. De acuerdo con al-Baqqār, es un ciclo de 75 años $\left(360^{\circ} / 4 ; 48^{\circ}\right)$ en el que 1 año equivale a $4 ; 48^{\circ} ; 1$ mes es igual a $0 ; 24^{\circ}$ y 1 día, a $0 ; 0,48^{\circ}$. Para Ibn al-Bannā' e Ibn 'Azzūz, el ciclo del dawr medio es de 72 años $\left(360^{\circ} / 5^{\circ}\right)$ en el que 1 año equivale a $5^{\circ} ; 1$ mes es igual a $0 ; 25^{\circ}$ y 1 día es igual a $0 ; 0,50^{\circ}$.

Según el texto, este ciclo (75/72 años) concuerda con la duración de la vida humana. El astrólogo andalusí al-Istiŷ̄ aclara que ${ }^{45}$ «éste es el periodo en el que el hombre puede llevar una vida activa y ocuparse de las cosas: si lo sobrepasa, su actividad disminuye».

[21]. El dawr medio recibe también el nombre de la prorrogación al-firdārī (altasyìr al-firdārî) ya que, de acuerdo con el texto, su ciclo de 75 años se corresponde con las firdārăt de los siete planetas y de los dos nodos lunares. La expresión firdār de los siete planetas alude a un sistema de origen persa en el que la vida humana se distribuye en una serie de periodos o firdār (plural: firdārāt) cada uno gobernado por un planeta diferente ${ }^{46}$. Si se trata de una natividad diurna, el Sol gobierna el primer periodo (de 10 años) al que le siguen los periodos de Venus (8 años), Mercurio (13 años), la Luna (9 años), Saturno (11 años), Júpiter (12 años) y Marte (7 años). En el

${ }^{43}$ De esta obra se conserva el libro décimo, véase TOLL, Christopher. "Al-Hamdān̄̄, Abū Muhammad al-Hasan ibn Ahmad ibn Ya'qūb", en Ch. Coulston Gillispie (eds.) Dictionary of Scientific Biography VI. New York: American Council of Learned Societies, 1972, 79-80; KING, David A. Mathematical Astronomy in Medieval Yemen. A Bio-Bibliographical Survey, vol. 4. Malibu: Publications of the American Research Center in Egypt, 1983, 19-20. Al-Hamdānī fue un autor conocido entre los astrólogos occidentales como Ibn Abī-l-Riỵāl (c. 965-1050), Șā‘id al-Andalusī o al-Istiŷn, véase BŪ 'ALWĀN, Hayāt. Tabaqāt, 66, 149; BLACHËRE, Régis. Șā'id al-Andalusī, 53, 115; MAÍlLO SALGADO, Felipe. Șāid al-Andalusī, Libro de las categorías, 57, 114; LLAVERO RUÍZ, Eloísa y MARTÍNEZ LORCA, Andrés. Historia de la filosofia, 76, 134; SAMSÓ, Julio y BERRANI, Hamid. "The Epistle", 182, 194, 231; DÍAZ-FAJARDO, Montse. "El capítulo sobre el tasyīr en al-Bāri" de Ibn Abī-l-Riŷāl y su traducción alfonsí". Al-Qantara, (en prensa), sección 5.

${ }^{44}$ SAMSÓ, Julio y BERRANI, Hamid. "The Epistle", 194.

${ }^{45}$ SAMSÓ, Julio y BERRANI, Hamid. "The Epistle", 196.

${ }^{46}$ Al-Bīrūn̄i, al-Tafhīm (traducción de RAMSAY WRIGHT, Robert. Kitāb al-tafhīm, 239 y 255); KENNEDY, Edward S. "The World-Year Concept", 356-358; Abū Ma‘šar, Mujtașar (edición y traducción de BURNETT, Charles, YAMAMOTO, Keiji y YANO, Michio. Abū Ma šar, The abbreviation of the Introduction to Astrology. Leiden, New York, Köln: Islamic Philosophy Theology and Science, 1994, 80-81). 
caso de natividades nocturnas la sucesión se inicia con la Luna. El último periodo lo gobiernan los dos nodos lunares ( 3 años el nodo ascendente y 2 años el nodo descendente). La suma de los años que comprende cada uno de los periodos es de 75 años.

[23]; [25]. Con las fracciones de este ciclo se utiliza el método de la progresión sobre la eclíptica al igual que en el dawr mayor. Además de los tres astrólogos que nos ocupan, sólo lo utiliza al-Istîŷi ${ }^{47}$ con un ciclo de 75 años.

[24]; [26]. Al-Baqqār emplea el mismo procedimiento que en el ciclo anterior para hallar la fecha del suceso.

\subsection{EL DAWR MENOR: [27]-[31]}

[29]. Es un ciclo de 12 años $\left(360^{\circ} / 30^{\circ}\right)$ en el que 1 año es igual a $30^{\circ} ; 1$ mes equivale a $2 ; 30^{\circ}$ y 1 día es igual a $0 ; 5^{\circ}$.

[27]; [30]. Según el texto, se denomina prorrogación cíclica (al-tasyīr al-dawrì) y dawr menor. De acuerdo con Ibn 'Azzūz, la comunidad de los astrólogos lo llama el signo del término (burŷ al-intihā').

[31]. El tipo de prorrogación que se emplea con el dawr menor es, como he avanzado, el método de la progresión sobre la eclíptica. Este ciclo y su fracción (1 año $=30^{\circ}$ ) fue el más utilizado de los tres dawr y se encuentra en una gran variedad de fuentes como Doroteo de Sidón ${ }^{48}$ (fl. siglo I), Awmāniyūs ${ }^{49} /$ Ammonius de la escuela de Alejandría (c. siglo VI), Abū Yūsuf al-Kindī, al-Jașībī ${ }^{\text {s0 }}$ (fl. 844), Abū Ma‘šar ${ }^{51}$, Ibn Abī-l-Riŷāl ${ }^{52}$, Kūšyār ibn Labbānn ${ }^{53}$, al-Qabīṣ̦ ${ }^{54}$, Ibn Qunfud ${ }^{55}$ o alIstiŷ̄i ${ }^{56}$, además de en Ibn al-Bannā', Ibn 'Azzūz y al-Baqqār.

${ }^{47}$ SAMSÓ, Julio y BERRANI, Hamid. "The Epistle”, 197.

${ }^{48}$ En su obra astrológica sobre los natalicios (parte IV, capítulo 1) editada y traducida por PINGREE, David. Dorotheus Sidonius, Carmen Astrologicum, Interpretationem arabicam in linguam anglicam versam una cum Dorothei fragmentis et graecis et latinis, edidit David Pingree. Leipzig: Bibliotheca Scriptorum Graecorum et Romanorum Teubneriana, 1976, 90 (texto árabe), 245 (traducción).

${ }^{49}$ En su Kitāb al-fușūl, según al-Baqqār (al-Adwār, parte IV, capítulo 5; ms. H8, fol. 104r; ms. H5, pág. $35 ; \mathrm{ms}$. E, fol. 255r) quien relaciona a este astrónomo con el burŷ al-muntahà (otra de las denominaciones que recibe el dawr menor). Al-Baqqār menciona otra obra en la que aparece este ciclo, el Kitāb al-amtāal li-l-furs, aunque no queda claro si la atribuye a Awmāniyūs o habría que leer: el Kitāb al-amtāal de los persas.

${ }^{50}$ Estos dos autores (al-Kindī y al-Jașībī) son citados por al-Baqqār (al-Adwār, parte V, capítulo 2; ms. H8 fol. 112 r; ms. H5 pág. 51; ms. E fol. 263r). Del primero, menciona el Kitāb taḥāwīl sin̄i-l'ālam (al-Baqqār podría aludir a la obra conservada de al-Kindī, Kitāb siñ̄-l-'ālam, véase SEZGIN, Fuat. $G A S, 130-134$; para otra posible identificación de esta obra, SAMSÓ, Julio y BERRANI, Hamid. "The Epistle", 194, nota 83). De al-Jașībī (Ibn al-Jașīb), al-Baqqār menciona su obra Taḥāwīl sinī-l-mawālīd (SEZGIN, Fuat. GAS, 123).

${ }^{51}$ En al-Milal I, 1, edición y traducción de YAMAMOTO, Keiji y BURNETT, Charles. $A b \bar{u}$ Ma ‘̌sar on Historical Astrology, 27, [31].

${ }_{52}^{52}$ DÍAZ-FAJARDO, Montse. "El capítulo", sección 2.2.

${ }^{53}$ En al-Madjal fí șinā'at aḥkām al-nuŷūm (parte III, capítulo 20), YANO, Michio. Kūšyār ibn Labbān's Introduction to Astrology. Edited and Translated by Michio Yano. Tokyo: Studia Culturae Islamicae 62, Institute for the Study of Languages and Cultures of Asia and Africa, 1997, [4]-[7].

${ }^{54}$ En al-Madjal ilà sinā'at aḥkām al-nuŷūm (parte IV), edición y traducción de BURNETT, Charles, YAMAMOTO, Keiji y YANO, Michio. Al-Qabīṣ̄ (Alcabitius), 116-119 [8].

${ }^{55}$ En Šarh raŷaz Ibn Abī-I-Riȳāl, ms. 916 (fols. 137v-138r) de la Biblioteca de El Escorial. Marc Oliveras Busquets, Universitat de Barcelona, ha realizado una edición de esta obra en su tesis doctoral. 


\section{CONCLUSIONES}

Los sistemas de ciclos de herencia india y persa, como el de Abū Ma‘šar, se caracterizan por la inclusión de grandes periodos de tiempo que rotan constantemente a partir de una fecha mítica y se desarrollan en la literatura astrológica histórica y mundial.

Los cuatro ciclos del Método son apropiados para la duración de la vida humana. Esto determina sus características: son periodos de tiempo cortos que se prorrogan a partir de un indicador celeste significativo y se desarrollan en la literatura astrológica genetlíaca.

Se podría decir que el Método es producto de materiales de distinta tradición: concentra los ciclos menores del sistema de Abū Ma`šar pero, al mismo tiempo, dos de sus ciclos, la qisma y el dawr menor, se encuentran en fuentes griegas.

La aplicación de la doctrina de los ciclos y la prorrogación a la astrología genetlíaca sea quizá la causa de su aprobación y permanencia en el Magreb. Así como la literatura astrológica histórica y mundial fue elaborada por astrólogos relacionados con los círculos de la corte, los horóscopos individuales podían ser parte del trabajo de un espectro más amplio de astrólogos ${ }^{57}$ y ser requeridos por sectores diversos de la sociedad medieval.

\section{TRADUCCIÓN DEL TEXTO DE AL-BAQQĀR}

[1] Capítulo primero de la parte quinta. Conocimiento de las clases de prorrogaciones características de los natalicios. Son cuatro clases.

[2] Sobre las prorrogaciones de esta clase numerosa e importante, has de saber que

\footnotetext{
Véase también, SAMSÓ, Julio. "La Urŷūza de Ibn Abī 1-Riŷāl y su comentario por Ibn Qunfud: astrología e historia en el Magrib en los siglos XI y XIV (I)". Al-Qantara XXX 1, (2009), 7-39; SAMSO, Julio. "La Urŷūza de Ibn Abī l-Riŷāl y su comentario por Ibn Qunfuḍ: astrología e historia en el Magrib en los siglos XI y XIV (II)". Al-Qantara XXX 2, (2009), 321-360.

${ }^{56}$ En su Risāla, véase SAMSÓ, Julio y BERRANI, Hamid. "World Astrology", 300; SAMSÓ, Julio y BERRANI, Hamid. "The Epistle", 184-185 [12].

${ }^{57}$ Sobre las condiciones del trabajo del astrólogo, véase SALIBA, George. "The Role of the Astrologer in Medieval Islamic Society". Bulletin d'Etudes Orientales 44, (1992), 45-67; NORTH, John David. "Scholars and power: astrologers at the courts of Medieval Europe", en J. Batlló Ortiz, P. Bernat López y R. Puig Aguilar (coord.) VI trobada d'História de la Ciència $i$ de la Tècnica. Barcelona: Societat Catalana d'Història de la Ciència i de la Tècnica, 2002, 13-28; BRENTJES, Sonja. "Courtly patronage of the ancient sciences in post-classical Islamic societies". Al-Qantara XXIX 2, (2008), 403-436. Sobre la aceptación de la astrología en al-Andalus, véase SAMSÓ, Julio. "Sobre el astrólogo "Abd al-Wāḥid b. Isḥāq al-Ḍabbī (fl. c. 788- c. 852)". Anaquel de Estudios Árabes 12, (2001), 657-669 (reimpresión en Astrometeorología y Astrología, no X); RIUS, Mònica. "La actitud de los emires cordobeses hacia los astrólogos: entre la adicción y el rechazo", en C. de la Puente (eds.) Estudios Onomástico-Biográficos de al-Andalus (Identidades marginales) XIII. Madrid: Consejo Superior de Investigaciones Científicas, 2003, 517-549; FORCADA, Miquel. "Astronomy, Astrology and the Sciences of the Ancients in Early al-Andalus $\left(2^{\text {nd }} / 8^{\text {th }}-3^{\text {rd }} / 9^{\text {th }}\right.$ Centuries $)$ ". Zeitschrift für Geschichte der Arabisch-Islamischen Wissenschaften 16, (2004-2005), 1-74.
} 
[[3]] los científicos divergieron en los modos de calcularlas pero yo me baso, de todas ellas, en lo más correcto que he encontrado y que encontraron quienes nos precedieron de acuerdo con la experiencia y el examen y según lo que la analogía racional y la ley física exigen: es el método de la comunidad de los astrólogos.

[4] Son cuatro clases.

[5] Clase primera del capítulo primero de la parte quinta. Es la mencionada por la comunidad de los expertos

[[6]] Se trata de que prorrogues los indicadores desde las posiciones radicales, para cada grado un año y para cada mes su parte y para cada día su parte del grado.

[7] Se logra de estas prorrogaciones, del grado del ascendente o de cualquier indicador que fuera que pase, en el cuadrante en el que se encuentre, por todas las luces de los siete planetas a través de alguno de los aspectos mencionados.

[8] Esta prorrogación se denomina la prorrogación de la qisma.

[9] Ya la hemos explicado con anterioridad en este libro suficientemente.

[10] Clase segunda del capítulo primero de la parte quinta. Explicación de la prorrogación natural característica del género humano

[[11]] Se trata de que prorrogues los indicadores desde los grados de sus posiciones radicales, para cada año tres grados. La parte que corresponde a un mes es de quince minutos y la parte que corresponde a un día es de treinta segundos.

[[12]] Esta clase de prorrogación se llama dawr (ciclo) mayor porque completa el círculo de la esfera en su totalidad en ciento veinte años solares que es el periodo natural de la vida humana.

[[13]] A través de esta prorrogación se aclara por qué la consumación de la vida humana se encuentra entre la edad de sesenta y ochenta años: se debe a que la prorrogación llega con este ciclo hasta la casa [séptima] que está en oposición al ascendente y es su contraria y hasta la casa [octava] que es la casa de los bienes y lo efimero.

[14] Esta clase de prorrogación la mencionó al-Hamdānī en el Kitāb sarā’ir al-hikma.

[15] Si quieres calcularla, multiplica el número de años completos solares transcurridos desde el nacimiento por tres grados. El resultado son grados eclípticos. Los sumas a la posición de uno de los indicadores, obtendrás la posición del término de la prorrogación natural en la eclíptica.

[16] Con la fracción de la posición buscada [que] no llegue a tres grados [es decir, el arco del tasyīr correspondiente a un año], toma [en la tabla de fracciones de un año] lo que corresponda a cada parte de la fracción: los días del año, las horas y sus minutos y súmalo a la fecha del aniversario, será ese momento el momento del suceso ya fuera favorable o lo contrario.

[17] Si lo deseas mediante la tabla, entra con los años completos solares del recién nacido en la columna de los años colectos y en la de los años simples 
y toma lo que esté frente a ellos en cuanto a signos, grados y minutos. Juntas eso y lo sumas a la posición sidérea del indicador y tomas la cantidad que exceda a las revoluciones completas, el resultado es la posición de la prorrogación natural para el dawr mayor. El inicio es desde el punto vernal. [18] La fracción de la posición buscada de la prorrogación [que] no llegue a tres grados, entra con ella en la tabla de las fracciones del año y toma los días, las horas y sus minutos. Súmalo a la fecha del aniversario, será la fecha buscada. Conoce eso por la potestad de Dios, ensalzado sea.

[19] Clase tercera del capítulo primero de la parte quinta. Explicación de la prorrogación al-firdā̄ī

[[20]] Es la prorrogación de los indicadores en los natalicios desde los grados de sus posiciones radicales para cada año cuatro grados cuarenta y ocho minutos. La parte de un día es de cuarenta y ocho segundos. Esta clase de prorrogación se llama dawr medio porque completa el círculo de la esfera en setenta y cinco años, el cual representa la consumación de la vida del hombre.

[[21]] Se denomina, también, la prorrogación al-firdārī debido a que su ciclo coincide con el número de los años de las firdārāt de los siete planetas y de los dos nodos lunares.

[22] Abū Marwān al-Istiŷ̀̄ dijo: «hemos experimentado este tipo de prorrogación y hemos descubierto que constituye una señal patente, clara para indicar la dicha y lo contrario a ésta» ${ }^{58}$.

[23] Si quieres calcularla, multiplica el número de años completos solares transcurridos desde el nacimiento por cuatro grados y cuatro quintos de grado. El resultado son grados eclípticos. Los sumas a la posición de uno de los indicadores, obtendrás la posición del término de la prorrogación alfirdārī en la eclíptica.

[24] Con la fracción de la posición buscada [que] no llegue a la fracción del arco del tasyīr correspondiente a un año, toma [en la tabla de fracciones de un año] lo que corresponda a cada parte de la fracción: los días del año, las horas y sus minutos y súmalo a la fecha del aniversario, será ese momento el momento del suceso ya fuera favorable o lo contrario.

[25] Si lo deseas mediante la tabla, entra con los años completos solares del recién nacido en la columna de los años colectos y en la de los años simples y toma lo que esté frente a ellos en cuanto a signos, grados y minutos. Juntas eso y lo sumas a la posición sidérea del indicador y tomas la cantidad que exceda a las revoluciones completas, el resultado es la posición de la prorrogación natural para el dawr medio. El inicio es desde el punto vernal. [26] La fracción de la posición buscada de la prorrogación [que] no llegue a cuatro grados y cuatro quintos de grado, entra con ella en la tabla de fracciones de un año y toma los días, las horas y sus minutos. Súmalo a la

\footnotetext{
${ }^{58}$ Fol. 12v de la Risāla de al-Istiŷi. SAMSÓ, Julio y BERRANI, Hamid. “The Epistle”, 197.
} 
fecha del aniversario, será la fecha buscada. Conoce eso por la bendición de Dios, ensalzado sea.

[27] Clase cuarta del capítulo primero de la parte quinta. Explicación de la prorrogación cíclica

[[28]] Es la prorrogación de los indicadores mencionados desde el grado del ascendente, si así lo deseas, o desde el grado de cualquier indicador que quieras.

[[29]] Para cada año treinta grados, su parte de un mes es de dos grados y medio y su parte de un día es de cinco minutos.

[[30]] Esta clase de prorrogación se llama dawr menor porque completa el círculo de la esfera en doce años, luego se traslada a otro ciclo de acuerdo con esta clase hasta completar el final de la vida.

[31] Ya hemos mencionado ampliamente esta prorrogación anteriormente en este libro nuestro dentro de otra clase diferente.

\begin{tabular}{|c|c|c|c|}
\hline \multicolumn{4}{|c|}{ 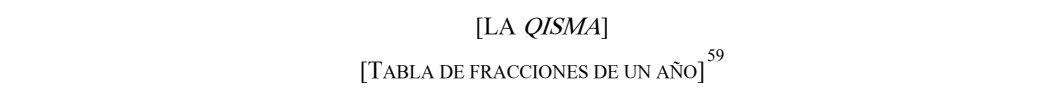 } \\
\hline$[$ ARCO DEL $T A S Y \bar{R} \bar{R}] 60$ & [TIEMPO] & 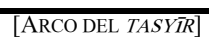 & [TIEMPO] \\
\hline $02{ }^{\prime}$ & $012 \mathrm{~d} 04 \mathrm{~h} 12 \mathrm{~m}^{61}$ & $32^{\prime}$ & 194d 19h $12 \mathrm{~m}$ \\
\hline $04^{\prime}$ & 024d 08h 24m & $34^{\prime}$ & $206 \mathrm{~d} 23 \mathrm{~h} 24 \mathrm{~m}$ \\
\hline 06 & $036 \mathrm{~d} 12 \mathrm{~h} 36 \mathrm{~m}$ & $36^{\prime}$ & $219 \mathrm{~d} 03 \mathrm{~h} 36 \mathrm{~m}$ \\
\hline 08 & 048d 16h 48m & 38 & $231 \mathrm{~d} 07 \mathrm{~h} 48 \mathrm{~m}$ \\
\hline $10^{\prime}$ & 060d 21h 00m & $40^{\prime}$ & $243 \mathrm{~d} 12 \mathrm{~h} 00 \mathrm{~m}$ \\
\hline $12^{\prime}$ & $073 \mathrm{~d} 01 \mathrm{~h} 12 \mathrm{~m}$ & $42^{\prime}$ & $255 \mathrm{~d} 16 \mathrm{~h} 12 \mathrm{~m}$ \\
\hline $14^{\prime}$ & $085 \mathrm{~d} 05 \mathrm{~h} 24 \mathrm{~m}$ & $44^{\prime}$ & $267 \mathrm{~d} 20 \mathrm{~h} 24 \mathrm{~m}$ \\
\hline $16^{\prime}$ & 097d 09h 36m & $46^{\prime}$ & $280 \mathrm{~d} 00 \mathrm{~h} 36 \mathrm{~m}$ \\
\hline $18^{\prime}$ & 109d 13h 48m & $48^{\prime}$ & 292d 04h 48m \\
\hline $20^{\prime}$ & $121 \mathrm{~d} 18 \mathrm{~h} 00 \mathrm{~m}$ & $50 ’$ & 304d 09h 00m \\
\hline $22^{\prime}$ & $133 \mathrm{~d} 22 \mathrm{~h} 12 \mathrm{~m}$ & $52^{\prime}$ & $316 \mathrm{~d} 13 \mathrm{~h} 12 \mathrm{~m}$ \\
\hline $24^{\prime}$ & $146 \mathrm{~d} 02 \mathrm{~h} 24 \mathrm{~m}$ & $54^{\prime}$ & $328 \mathrm{~d} 17 \mathrm{~h} 24 \mathrm{~m}$ \\
\hline $26^{\prime}$ & $158 \mathrm{~d} 06 \mathrm{~h} 36 \mathrm{~m}$ & $56^{\prime}$ & $340 \mathrm{~d} 21 \mathrm{~h} 36 \mathrm{~m}$ \\
\hline $28^{\prime}$ & 170d $10 \mathrm{~h} 48 \mathrm{~m}$ & $58^{\prime}$ & $353 \mathrm{~d} 01 \mathrm{~h} 48 \mathrm{~m}$ \\
\hline $30^{\prime}$ & $182 \mathrm{~d} 15 \mathrm{~h} 00 \mathrm{~m}$ & $60 ’$ & $365 \mathrm{~d} 06 \mathrm{~h} 00 \mathrm{~m}$ \\
\hline
\end{tabular}

\footnotetext{
${ }^{59} \mathrm{El}$ título de la tabla que aparece en el manuscrito es: «Tabla de los días que corresponden a la prorrogación con los minutos del grado de la qisma en intervalos del año solar». Esta tabla se encuentra en el fol. 250v del ms. E y en la pág. 27 del ms. H5. Para cada minuto del arco de la prorrogación, al-Baqqār utiliza un parámetro de 6 días 2 horas 6 minutos.

${ }^{60}$ Esta columna se llama en el manuscrito: «Minutos y grados de la qisma».

${ }^{61}$ Es decir, 12 días 4 horas 12 minutos.
} 


\begin{tabular}{|c|c|c|c|}
\hline \multicolumn{4}{|c|}{ [EL DAWR MAYOR] } \\
\hline $\begin{array}{l}\text { [TIEMPO] } \\
\end{array}$ & ARCO DEL TASYITR & $\frac{1 \mathrm{TLT}}{[\mathrm{TIEMPO}]}$ & ARCO DEL TASYĪR \\
\hline 10 años & 1signo & 1 año & $3^{\circ}$ \\
\hline 20 & $2 \mathrm{~s}$ & 2 & $6^{\circ}$ \\
\hline 30 & $3 \mathrm{~s}$ & 3 & $9^{\circ}$ \\
\hline 40 & $4 \mathrm{~s}$ & 4 & $12^{\circ}$ \\
\hline 50 & $5 \mathrm{~s}$ & 5 & $15^{\circ}$ \\
\hline 60 & $6 \mathrm{~s}$ & 6 & $18^{\circ}$ \\
\hline 70 & $7 \mathrm{~s}$ & 7 & $21^{\circ}$ \\
\hline 80 & $8 \mathrm{~s}$ & 8 & $24^{\circ}$ \\
\hline 90 & $9 \mathrm{~s}$ & 9 & $27^{\circ}$ \\
\hline 100 & $10 \mathrm{~s}$ & 10 & $30^{\circ}$ \\
\hline \multicolumn{4}{|c|}{$[\mathrm{EL} D A W R \mathrm{MAYOR}]$} \\
\hline$\overline{\text { ARCO DEL TASYITR }}$ & [TIEMPO] & ARCO DEL TASYITR & [TIEMPO] \\
\hline $0 ; 15^{\circ}$ & 30d $10 \mathrm{~h} \mathrm{30m}$ & $1 ; 45^{\circ}$ & 213d 01h 30m \\
\hline $0 ; 30^{\circ}$ & $60 \mathrm{~d} 21 \mathrm{~h} 00 \mathrm{~m}$ & $2 ; 00^{\circ}$ & $243 \mathrm{~d} 12 \mathrm{~h} 00 \mathrm{~m}$ \\
\hline $0 ; 45^{\circ}$ & 91d $07 \mathrm{~h} 30 \mathrm{~m}$ & $2 ; 15^{\circ}$ & $273 \mathrm{~d} 22 \mathrm{~h} 30 \mathrm{~m}$ \\
\hline $1 ; 00^{\circ}$ & $121 \mathrm{~d} 18 \mathrm{~h} 00 \mathrm{~m}$ & $2 ; 30^{\circ}$ & $304 \mathrm{~d} 09 \mathrm{~h} \mathrm{00m}$ \\
\hline $1 ; 15^{\circ}$ & $152 \mathrm{~d} 04 \mathrm{~h} 30 \mathrm{~m}$ & $2 ; 45^{\circ}$ & $334 \mathrm{~d} 19 \mathrm{~h} \mathrm{30m}$ \\
\hline $1 ; 30^{\circ}$ & $182 \mathrm{~d} 15 \mathrm{~h} 00 \mathrm{~m}$ & $3 ; 00^{\circ}$ & $365 \mathrm{~d} 06 \mathrm{~h} 00 \mathrm{~m}$ \\
\hline \multicolumn{4}{|c|}{ [EL $D A W R$ MEDIO] } \\
\hline [TIEMPO] & ARCO DEL TASYTR & [TIEMPO] & $\overline{\text { ARCO DEL TASYT̃R }}$ \\
\hline 10 años & $01 \mathrm{~s} 18^{\circ}$ & 1 año & 0s $04 ; 48^{\circ}$ \\
\hline 20 & $03 \mathrm{~s} 06^{\circ}$ & 2 & $0 \mathrm{~s} 09 ; 36^{\circ}$ \\
\hline 30 & $04 \mathrm{~s} 24^{\circ}$ & 3 & os $14 ; 24^{\circ}$ \\
\hline 40 & $06 \mathrm{~s} 12^{\circ}$ & 4 & Os $19 ; 12^{\circ}$ \\
\hline 50 & $08 \mathrm{~s} 00^{\circ}$ & 5 & $0 \mathrm{~s} 24 ; 00^{\circ}$ \\
\hline 60 & $09 \mathrm{~s} 18^{\circ}$ & 6 & 0s $28 ;[4] 8^{\circ 65}$ \\
\hline 70 & $11 \mathrm{~s} 06^{\circ}$ & 7 & $1 \mathrm{~s} 03 ; 36^{\circ}$ \\
\hline & & 8 & $1 \mathrm{~s} 08 ; 24^{\circ}$ \\
\hline & & 9 & 1s $13 ; 12^{\circ}$ \\
\hline & & 10 & $1 \mathrm{~s} 18 ; 00^{\circ}$ \\
\hline
\end{tabular}

${ }^{62}$ El nombre de la tabla que aparece en el manuscrito es: «Tabla del al-tasyīr al-tabī ‘̄i para los natalicios en años colectos y simples». Las columnas «Tiempo» se denominan «Años colectos» y «Años simples». Esta tabla se encuentra en el fol. 260r del ms. E y en la pág. 45 del ms. H5.

${ }^{63}$ El nombre de la tabla que aparece en el manuscrito es: «Tabla del al-tasyīr al-tabí $\bar{T}^{\top} \overline{\mathrm{T}}$ en fracciones del aniversario del año (al-sana al-tạ̣wīlìya)». Se encuentra en el fol. 260r del ms. E y en la pág. 45 del ms. H5.

${ }^{64}$ Tabla llamada en el manuscrito: «Tabla del al-tasyīr al-fírdārī para los años colectos y simples». Se encuentra en el fol. 261r del ms. E. El ms. H5 carece de esta tabla. 


\begin{tabular}{|c|c|c|c|c|}
\hline \multicolumn{5}{|c|}{$\begin{array}{c}\text { [EL } D A W R \text { MEDIO] } \\
{\left[\text { [TABLA DE FRACCIONES DE UN AÑO] }^{66}\right.}\end{array}$} \\
\hline ARCO DEL TASYīR & \multicolumn{2}{|l|}{ [TIEMPO] } & \multicolumn{2}{|l|}{ ARCO DEL TASYITR } \\
\hline $\begin{array}{l}0 ; 24^{\circ} \\
0 ; 48^{\circ} \\
1 ; 12^{\circ} \\
1 ; 36^{\circ} \\
2 ; 00^{\circ} \\
2 ; 24^{\circ}\end{array}$ & \multicolumn{2}{|c|}{$\begin{array}{l}30 \mathrm{~d} 10 \mathrm{~h} 30 \mathrm{~m} \\
60 \mathrm{~d} 21 \mathrm{~h} 00 \mathrm{~m} \\
91 \mathrm{~d} 07 \mathrm{~h} 30 \mathrm{~m} \\
121 \mathrm{~d} 18 \mathrm{~h} 00 \mathrm{~m} \\
152 \mathrm{~d} 04 \mathrm{~h} 30 \mathrm{~m} \\
182 \mathrm{~d} 15 \mathrm{~h} 00 \mathrm{~m}\end{array}$} & $\begin{array}{l}2 ; 48^{\circ} \\
3 ; 12^{\circ} \\
3 ; 36^{\circ} \\
4 ; 00^{\circ} \\
4 ; 24^{\circ} \\
4 ; 48^{\circ}\end{array}$ & $\begin{array}{l}\text { 213d } 01 \mathrm{~h} 30 \mathrm{~m} \\
243 \mathrm{~d} 12 \mathrm{~h} 00 \mathrm{~m} \\
273 \mathrm{~d} 22 \mathrm{~h} 30 \mathrm{~m} \\
304 \mathrm{~d} 09 \mathrm{~h} 00 \mathrm{~m} \\
334 \mathrm{~d} 19 \mathrm{~h} 30 \mathrm{~m} \\
365 \mathrm{~d} 06 \mathrm{~h} 00 \mathrm{~m}\end{array}$ \\
\hline \multicolumn{5}{|c|}{$\begin{array}{c}\text { [EL } D A \text { WR MENOR] } \\
\text { [TABLA DE FRACCIONES DE UN ANNO] }^{67}\end{array}$} \\
\hline [ARCO DEL TASYRR] & [TIEMPO] & TARC & DEL TASYTR] & [TIEMPO] \\
\hline $\begin{array}{l}01^{\mathrm{o}} \\
02^{\mathrm{o}} \\
03^{\mathrm{o}} \\
04^{\mathrm{o}} \\
05^{\mathrm{o}} \\
06^{\mathrm{o}} \\
07^{\mathrm{o}} \\
08^{\mathrm{o}} \\
09^{\mathrm{o}} \\
10^{\mathrm{o}} \\
11^{\mathrm{o}} \\
12^{\mathrm{o}} \\
13^{\mathrm{o}} \\
14^{\mathrm{o}} \\
15^{\mathrm{o}} \\
\end{array}$ & 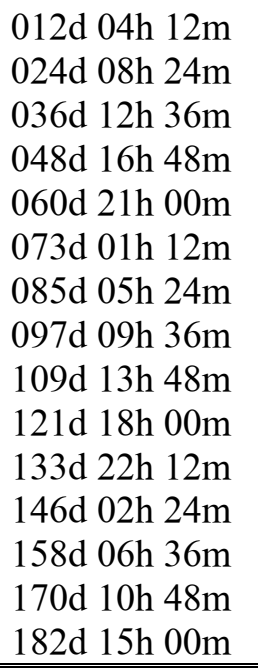 & $\begin{array}{l}16^{\circ} \\
17^{\circ} \\
18^{\circ} \\
19^{\circ} \\
20^{\circ} \\
21^{\circ} \\
22^{\circ} \\
23^{\circ} \\
24^{\circ} \\
25^{\circ} \\
26^{\circ} \\
27^{\circ} \\
28^{\circ} \\
29^{\circ} \\
30^{\circ}\end{array}$ & & 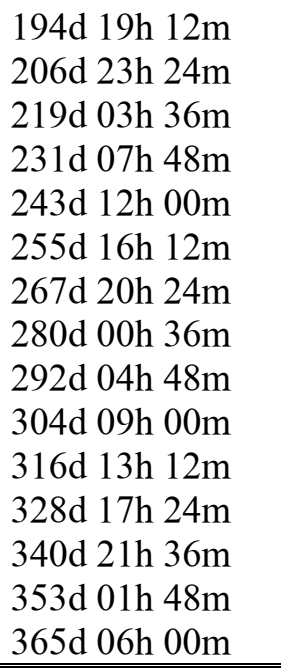 \\
\hline
\end{tabular}

\section{EDICIÓN DEL TEXTO DE AL-BAQQĀR}

He utilizado los símbolos siguientes en la edición: $\mathrm{E}=$ ms. 916 (Biblioteca de El Escorial); $\mathrm{H} 8=\mathrm{ms} .826$ (Biblioteca al-Hasaniyya, Rabat); $\mathrm{H} 5=\mathrm{ms} .5372$ (Biblioteca al-Hasaniyya, Rabat). El manuscrito base es el H8. Las tablas las he incorporado solamente en la traducción y las he editado siguiendo los mss. E y H5

\footnotetext{
${ }^{65} 0 \mathrm{~s} 28 ; 58^{\circ}$ en el ms.

${ }^{66}$ El nombre de la tabla que aparece en el manuscrito es: «Tabla del al-tasyīr al-firdārī en fracciones del aniversario del año». Se encuentra en el fol. $261 \mathrm{r}$ del ms. E. El ms. H5 carece de esta tabla.

${ }^{67} \mathrm{Su}$ título en el manuscrito es: «Tabla del al-tasyīr al-dawrī en intervalos del año solar» y se encuentra en el fol. $251 \mathrm{v}$ del $\mathrm{ms}$. E y en la pág. 29 del ms. H5. La tabla utiliza, sistemáticamente, 12 días 4 horas 12 minutos para cada grado del tasyîr.
} 
ya que el ms. H8 carece de ellas. He señalado con doble corchete los párrafos del texto del Método que se encuentran en Ibn al-Bannā', Ibn 'Azzūz y al-Baqqār.

[1] الفصل الأولّ من الباب الخامس في معرفة ما يخصّ المواليد من أنواع التسييرات وهي أربعة أنواع

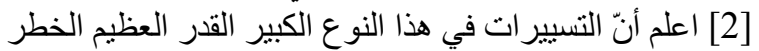

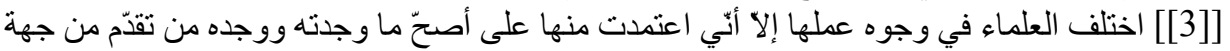

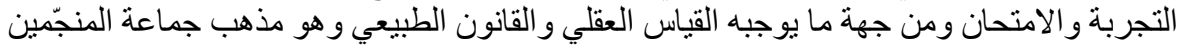

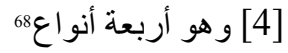

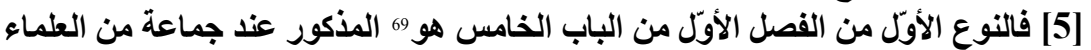

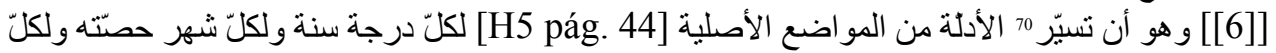

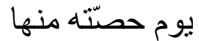

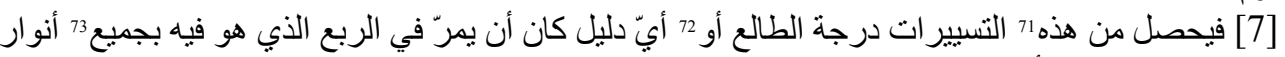
الكو اكب السبعة من أحد المناظر 74 المذكورة

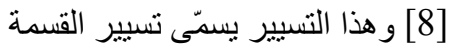

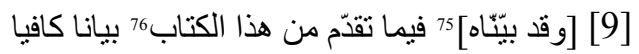

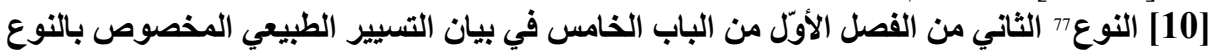

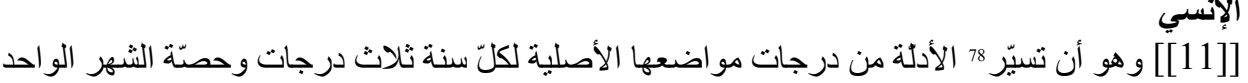

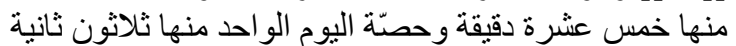

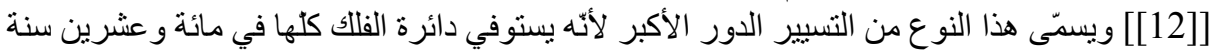

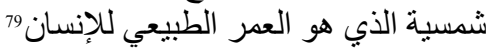

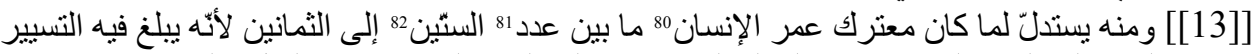

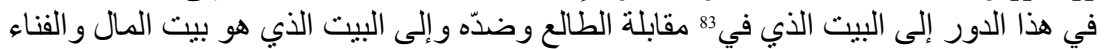

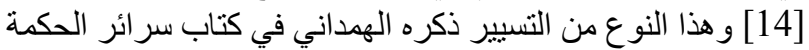

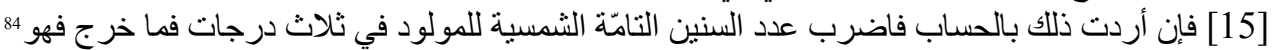

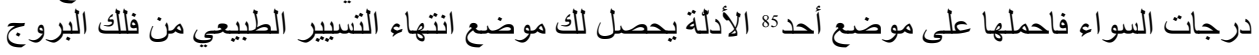

${ }^{68}$ H5 omite los párrafos [2]-[4].

${ }^{69} \mathrm{E}$ و و

${ }^{70} \mathrm{H} 8, \mathrm{H} 5$ y E تسيير

${ }^{71} \mathrm{H} 8, \mathrm{H} 5$ y E

${ }^{72}$ E 9

لجميع E النجانظمع

${ }^{74} \mathrm{H} 5$ الناظر

وقدّمناه

الباب

${ }^{77} \mathrm{H} 5$ فالنو

تسبير H8, H5 y

"لإنسن E

${ }^{80} \mathrm{E}$ الإنسن

عشرة:

السنين E2

${ }^{83} \mathrm{E}$ هو

فهي

${ }^{85}$ H5 escribe أحهي en el margen 


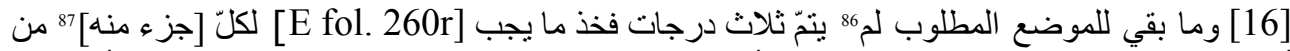
أيّام السنة و الساعات ودقائقها 88 واحمله على تأريخ التحويل يكن 89 ذللك الوقت وقت الحادث خير الكان أو ضدّه

[H8 fol. 109r]

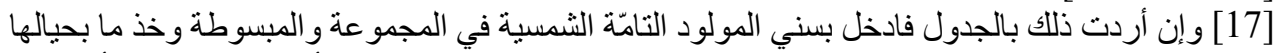

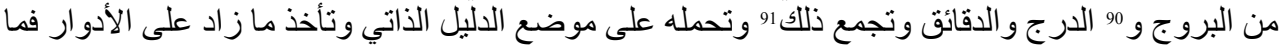

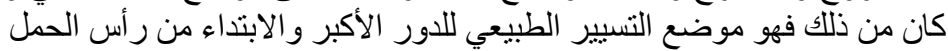

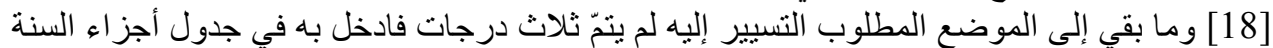

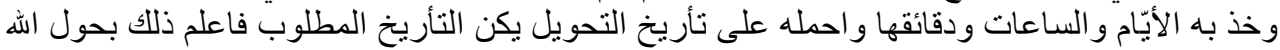

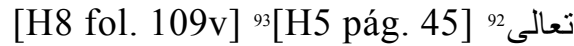

] [19] [النوع [الثالث من الفصل الأوّل من الباب الخامس في بيان التسبير الفرداري

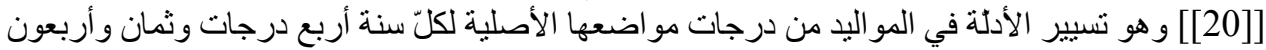

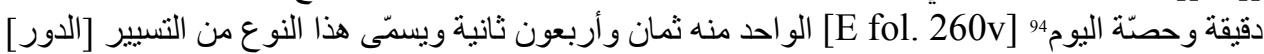

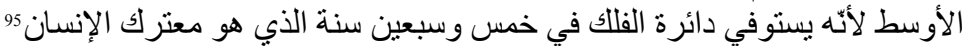

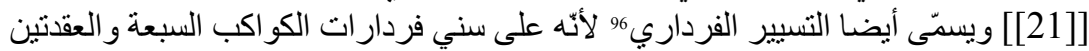

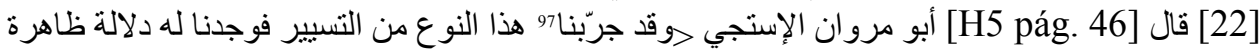

$$
\text { بيّنة } 98 \text { على السعادة وضدّها }
$$

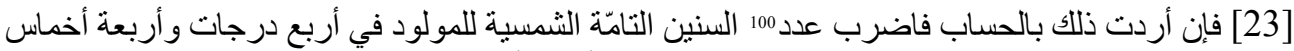

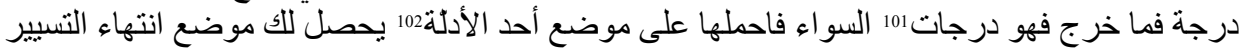

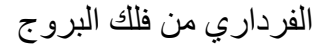

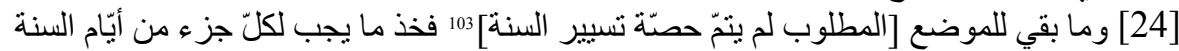

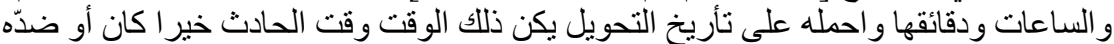

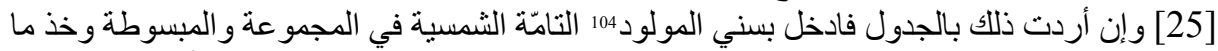

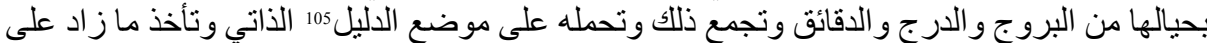
الأدو ار فما كان من ذللك فهو موضع التسيير الفرداري للأور الأوسط و الابتداء من رأس الحمل

${ }^{86} \mathrm{E}+\mathrm{H}$

جزئنيته

الخقائقَّ

يكون

أو

${ }^{91} \mathrm{E}$ añade

| E añade las tablas:

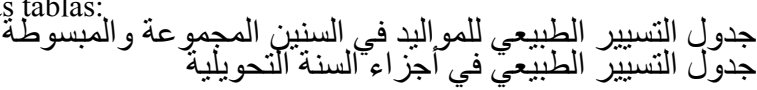

${ }^{93} \mathrm{H} 5$ añade las tablas:

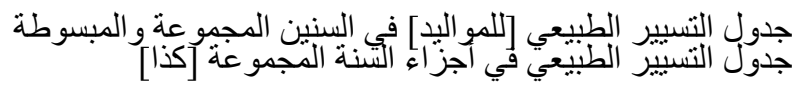

الشهر

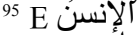

الافرداري

جدبثنا

معيّنة

${ }^{99}<>$ Al-Istiŷî, Risāla, edición de SAMSÓ, Julio y BERRANI, Hamid. “The Epistle”, 233.

${ }^{100} \mathrm{E}$ ع

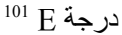

الدلالة

${ }^{103}$ H5 omite [ ] 
[26] وما بقي إلى الموضع المطلوب لم يتمّ أربع درجات و أربعة أخماس درجة فادخل به في جدول أيّام السنة

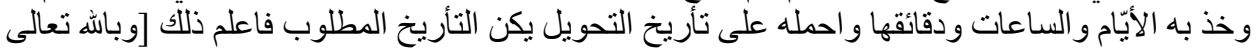

[H8 fol. 110r] [H5 pág. 47] [التوفيق]

[27] النوع الرابع من الفصل الأولّ من الباب الخامس في بيان التسيير الدوري

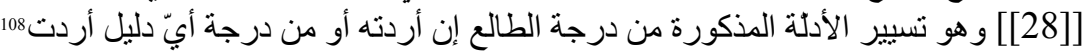

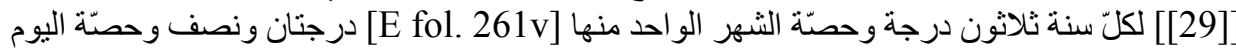
الو احد منها 109 خمس دقائق

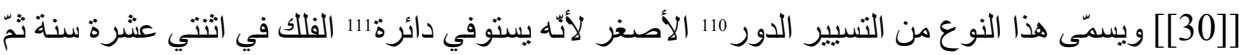

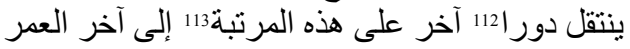
[31] فقد أتينا على114 مبسوط هذا التسبير فيما تقدّم في كتابنا هذا في غير آلير هذا النوع

\footnotetext{
المولد

${ }^{105} \mathrm{H} 8$ y H5 omiten الدليل

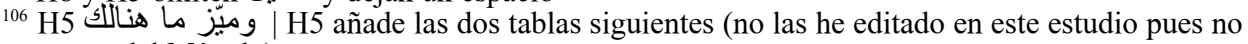
forman parte del Método):

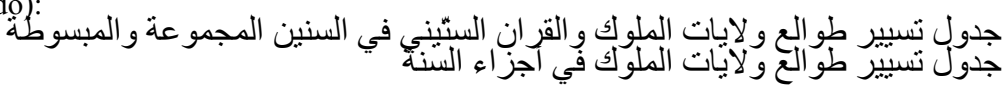

${ }^{107} \mathrm{E}$ añade las tablas:

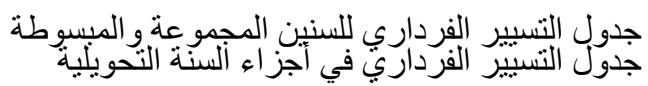

${ }^{108}$ H5 أردته

درجتان ونصف وحصّة اليوم الو احد منها ألمدنه E repite

${ }^{110}$ H5 escribe الدور en el margen

دارة

دور E دارة

الرتبة 113

على ع omite
} 